\title{
Application of a rating system to state clean indoor air laws (USA)
}

\author{
J F Chriqui, M Frosh, R C Brownson, D M Shelton, R C Sciandra, R Hobart, P H Fisher, \\ R el Arculli, M H Alciati
}

Tobacco Control 2002;11:26-34

See end of article for authors' affiliations

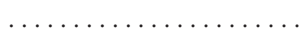

Correspondence to: Jamie F Chriqui, The MayaTech Corporation, 8737 Colesville Road, 7th Floor, Silver Spring, MD 20910-3921, USA;

jchriqui@mayatech.com.

Received 20 July 2001 and revision requested 21 September 2001

Accepted

20 November 2001

\begin{abstract}
Objective: To develop and implement a system for rating state clean indoor air laws.
Design: The public health interest of state clean indoor air laws is to limit non-smoker exposure to environmental tobacco smoke (ETS). Current estimates of health risks and methods available for controlling ETS provided a framework for devising a ratings scale. An advisory committee applied this scale to each of seven site specific smoking restrictions and two enforcement related items. For each item, a target score of +4 was identified. The nine items were then combined to produce a summary score for each state. A state that achieved the target across all nine items would receive a summary score of 36 points and be eligible to receive an additional 6 points for exceeding the target on six of the nine items, resulting in a maximum summary score of 42 points. Individual scores were also adjusted to reflect state level preemption measures. Each state's law was evaluated annually from 1993 through 1999.

Setting: USA.

Main outcome measure: A summary score measuring the extensiveness of the state's clean indoor air law.

Results: State laws restricting smoking in the seven individual locations of interest were relatively weak. The overall mean score across the location restrictions ranged from 0.72 in 1993 to 0.98 in 1999. Mean scores were higher for the enforcement items than for the location restrictions. Summary scores ranged from 0 to 20 in 1993 and 0 to 31 in 1994 through 1999. Average summary scores ranged from 8.71 in 1993 to 10.98 in 1999. By the end of 1999, scores increased for 22 states; however, between 1995 and 1997 there were no changes in the summary scores. Three states scored zero points across all years. From 1993 through 1999, there was a $41 \%$ increase in the number of states that had in place state level preemption measures.

Conclusion: The number of newly enacted state clean indoor air laws has remained relatively stagnant since 1995. With a few exceptions, as of the end of 1999, progress in enacting state laws to meet specified public health targets for reducing exposure to ETS was relatively low. Thus, state laws in the USA provide, on average, only minimal protection in specified areas and, given the increase in preemption, are increasingly undermining those passed in localities.
\end{abstract}

n 1986, the US Surgeon General and the National Research Council reported on scientific evidence that involuntary smoking is a cause of disease in non-smokers. ${ }^{12}$ Involuntary smoking is also referred to as non-smokers' exposure to environmental tobacco smoke (ETS). ETS is defined as a mixture of side stream smoke from a cigarette and mainstream smoke exhaled by a smoker. ${ }^{1}$ ETS has been widely studied for links to respiratory, carcinogenic, cardiovascular, and other illnesses. ${ }^{34}$ In a 1992 report, the US Environmental Protection Agency (EPA) designated ETS as a group A (known human) carcinogen. ${ }^{5}$ Based on subsequent studies, EPA findings relating to risks of ETS exposure and lung cancer remain authoritative. ${ }^{6}$ At the same time, the National Institute for Occupational Safety and Health (NIOSH) has classified ETS in the workplace as an occupational health hazard. ${ }^{7}$ Both the EPA and NIOSH have recommended eliminating non-smoker exposure to ETS. ${ }^{57}$ The 1992 EPA report also highlighted evidence that children who are exposed to ETS are at risk for illnesses, including asthma, respiratory tract infections, and middle ear disease. ${ }^{5}$

"Healthy People 2010"-a compendia of the federal government's national public health objectives-provides specific incentives for states to regulate smoking in public places. The report calls on each state to enact comprehensive clean indoor air laws that strictly limit smoking in public places and in public and private worksites. ${ }^{8}$

While a modest number of laws on smoking in indoor locations were in place in a number of states decades ago, scientific evidence supporting the conclusion that ETS is a disease causing agent developed over the past decade-and resulting recommendations for limiting exposure to ETS provided a framework for regulating ETS exposure. ${ }^{125}$ State legislatures responded with laws ranging from minimal restrictions on smoking to comprehensive restrictions on smoking in most public places. ${ }^{910}$

In order to provide comparative data on state legislation restricting indoor smoking, an advisory committee was convened by the National Cancer Institute (NCI) to develop a system for rating state clean indoor air laws; a rating system had previously been devised for rating state laws on youth access to tobacco. ${ }^{11}$ As Wakefield and Chaloupka note, such measures provide a unique opportunity to assess the affect of

Abbreviations: ASSIST, American Stop Smoking Intervention Study, EPA, Environmental Protection Agency; ETS, environmental tobacco smoke; $\mathrm{NCl}$, National Cancer Institute; $\mathrm{NIOSH}$, the National Institute for Occupational Safety and Health; SCLD, State Cancer Legislative Database 
Table 1 Targets for each item in clean indoor air score

\begin{tabular}{ll}
\hline Item & Target \\
\hline 1: Government worksites & Government worksites are 100\% smokefree, no exemptions \\
2: Private worksites & Private worksites are 100\% smokefree, no exemptions \\
3: Schools & No smoking permitted in schools during school hours or while school activities are being conducted \\
4: Childcare facilities & No smoking permitted during operating hours in childcare facilities (explicitly including licensed home based \\
& facilities) \\
5: Restaurants & Restaurants (explicitly including bar areas of restaurants) are $100 \%$ smoke-free \\
6: Retail stores & Retail stores or retail businesses open to the public are 100\% smoke-free \\
7: Recreational/cultural facilities & Recreational and cultural facilities are 100\% smoke-free \\
8: Penalties & Penalties or fines, applicable to smokers and to proprietors/employers, for any violation of clean indoor air \\
9: Enforcement & legislation \\
\hline
\end{tabular}

tobacco control inputs (for example, clean indoor air policies) on tobacco control outputs (for example, exposure to ETS). ${ }^{12}$ In fact, Luke and colleagues have demonstrated the ability to assess the relation between the state youth access ratings and youth smoking behaviour. ${ }^{13}$ For the current study, ratings for clean indoor air laws (in effect as of the end of 1993 through the end of 1999) in all 50 states and the District of Columbia (hereinafter referred to as "states") were based not only on whether the law restricts smoking in a particular type of location, but also on an ordinal coding of the type of restriction mandated for those locations.

The members of the NCI committee have experience in conducting policy research, implementing interventions, and analysing public health issues related to smoking. The committee used this experience to establish several goals it considered essential for developing a model to rate the wide range of state statutes restricting indoor smoking. The committee initially identified critical topic areas for clean indoor air legislation by consulting guidelines developed as part of the American Stop Smoking Intervention Study (ASSIST) - a joint project of NCI and the American Cancer Society that has developed cancer prevention and control programmes in 17 states. ${ }^{14}$ In addition, when developing criteria for the ratings structure, the committee reviewed data on the specifics of clean indoor air items as presented in state laws. Based on the ASSIST guidelines and this review, the committee developed nine categories for inclusion in this study: seven sites of restriction (that is, public worksites, private worksites, schools, childcare facilities, restaurants, retail stores, and recreational/cultural facilities) as well as penalty and enforcement items (table 1). This system is applicable both to laws that address places of employment generally (that is, California and Maryland) and to those laws that address specific location restrictions (for example, restaurants, schools, etc).

As of the end of 1999, public and private workplaces were covered by laws in 37 and 22 states, respectively, and data are emerging on the effects of various restrictions. ${ }^{15-23}$ Schools in 44 states and childcare facilities in 32 states were also covered by state laws that mandate some level of smoking restriction-indicating a strong public health interest in protecting children from ETS. ${ }^{54-26}$ Restaurants were covered under smoking laws in 31 states, and the impact of these laws has been examined in numerous studies. ${ }^{27-31}$ Although the implementation and effects of smoking restrictions on retail stores and recreational/cultural facilities are not well examined as discrete topics, such restrictions are a recognisable element of comprehensive clean indoor air laws ${ }^{1}$ and have a significant presence in states with less extensive regulation; more than half of the states have laws restricting smoking in these venues.

The nine items established for the rating system were designed to serve as an indication of the comprehensiveness of the effort by individual states to restrict indoor smoking. To this end, the committee identified four underlying goals for this study:

- to identify state specific smoking restrictions in seven indoor settings and the extent to which such restrictions may minimise exposure to ETS

- to delineate features of the law that narrow or otherwise limit its application

- to measure the degree to which the law defines penalties and enforcement

- and to ascertain whether state law preempts stronger local clean indoor air ordinances.

\section{DATA SOURCE AND METHODS}

The state clean indoor air legislative data used for this study were obtained from NCI's State Cancer Legislative Database (SCLD) program (http://www.scld-nci.net). SCLD contains information on the current status of each state's clean indoor air law as of the last day of each calendar year beginning with 1993. The current status records reflect all changes, including substantive amendments and repeals, since the law's inception. The 1993 through 1999 clean indoor air current status records were used to develop ratings for each of the nine areas addressed by this study.

The methodology developed to rate state clean indoor air laws was based on the model employed for the youth access to tobacco ratings. ${ }^{11}$ The clean indoor air ratings cover laws in effect at seven points in time- - the end of each year from 1993 through 1999. For each of these time points, a state's total summary score equals the sum of the state's ratings on each of the nine categories identified earlier. The total scores, therefore, indicate how closely the state laws approximated a series of seven target items identified as being important to limiting non-smoker exposure to ETS. While recognising that clean indoor air laws have been characterised as self enforcing, ${ }^{32}{ }^{33}$ the NCI committee felt that it was important to address penalties for violation of the state law and identification of specific enforcement bodies. Thus, the total scores could be divided into two components: seven of the target items specifically relate to controlling smoking in indoor locations and two of the target items address enforcement of the location items (table 1).

As with the youth access to tobacco ratings methodology, a "target" score of +4 was identified for each of the nine clean indoor air items to reflect the public health objectives for limiting non-smoker exposure to ETS. ${ }^{11}$ As table 1 and the appendix indicate, for the seven location restrictions (that is, items 1-7), the target score reflects a total ban on smoking. Such a ban represents the most stringent possible restriction and renders moot the scientific assessment of whether exposure to ETS is minimised or eliminated. For six of the nine items (government worksites, private worksites, schools, childcare facilities, penalties, and enforcement), the committee felt that 
Table 2 Mean scores (without preemption penalty) by category, 1993 through 1999

\begin{tabular}{|c|c|c|c|c|c|c|c|c|}
\hline \multirow[b]{2}{*}{ Category } & & \multicolumn{7}{|l|}{ Year } \\
\hline & & 1993 & 1994 & 1995 & 1996 & 1997 & 1998 & 1999 \\
\hline Individual rating item & $\begin{array}{l}\text { Maximum } \\
\text { points* }\end{array}$ & & & & & & & \\
\hline 1. Government worksites & 5 & 0.84 & 0.84 & 0.92 & 0.92 & 0.92 & 0.92 & 0.96 \\
\hline 2. Private worksites & 5 & 0.39 & 0.45 & 0.53 & 0.53 & 0.53 & 0.53 & 0.53 \\
\hline 3. Schools & 5 & 1.06 & 1.35 & 1.59 & 1.59 & 1.59 & 1.59 & 1.67 \\
\hline 4. Childcare facilities & 5 & 0.94 & 1.31 & 1.27 & 1.27 & 1.27 & 1.43 & 1.43 \\
\hline 5. Restaurants & 4 & 0.57 & 0.65 & 0.67 & 0.67 & 0.67 & 0.67 & 0.67 \\
\hline 6. Retail stores & 4 & 0.59 & 0.69 & 0.75 & 0.75 & 0.75 & 0.75 & 0.75 \\
\hline 7. Recreational/cultural facilities & 4 & 0.65 & 0.76 & 0.86 & 0.86 & 0.86 & 0.86 & 0.86 \\
\hline 8. Penalties & 5 & 1.82 & 2.00 & 2.04 & 2.04 & 2.04 & 2.10 & 2.10 \\
\hline 9. Enforcement & 5 & 1.84 & 1.96 & 1.96 & 1.96 & 1.96 & 2.00 & 2.02 \\
\hline \multicolumn{9}{|l|}{ Composite rating items } \\
\hline Location restrictions & & 0.72 & 0.86 & 0.94 & 0.94 & 0.94 & 0.96 & 0.98 \\
\hline Penalty and enforcement items & & 1.83 & 1.98 & 2.00 & 2.00 & 2.00 & 2.05 & 2.06 \\
\hline Overall mean for all items & & 0.97 & 1.10 & 1.18 & 1.18 & 1.18 & 1.21 & 1.22 \\
\hline
\end{tabular}

a bonus point (over and above the target) was warranted when a state law exceeded the requirements of the target item. For example, for government and private worksites, a bonus point was assigned if a law prohibited smoking in both the worksite and the outdoor areas around such worksites. In such instances, a state was assigned a +5 rating.

A more difficult judgment for the committee was how to rank the restrictions that are less stringent than a total ban for the seven locations of interest. Examining methods for controlling ETS provided an obvious basis for discriminating among the options. ${ }^{34-38}$ Based on evidence from the research literature, the committee felt that smoking bans reduce exposure to ETS to a greater extent than do enclosed, separately ventilated designated smoking areas (which are reportedly $100 \%$ effective only under optimal circumstances) and ranked these two options as a +4 and +3 , respectively. ${ }^{36}{ }^{40}$ Moreover, the health benefits of a smokefree policy as compared to enclosed, separately ventilated smoking lounges may be a significant health issue for smokers, who are concentrated in a small area in such lounges. ${ }^{41}$ A score of +2 was assigned to items that limit smoking to enclosed areas without separate ventilation (thereby subjecting non-smokers to building wide recirculation of tobacco smoke). ${ }^{36}$ Items that permit unenclosed smoking areas were given the lowest ranking $(+1)$ because simple separation of smokers and non-smokers provides the least protection from ETS exposure. ${ }^{13} 36$ (The appendix delineates the scoring structure for each of the nine items.) State scores for categories that specify locations (items 1-7) were adjusted based on specific limitations or exemptions that narrowed coverage of the law. In general, the score was reduced by one point if a basic restriction was in place but a smaller class or category of individuals was excluded from the law. In some cases, however, the committee determined that explicit exemption of a significant class or category (for example, an exemption for private schools in a school smoking item or an exemption for restaurants serving fewer than 50 patrons in a restaurant smoking item) should result in a score of +1 . The committee considered data from the US Bureau of Labor Statistics ${ }^{42}$ to create specific values for government and private workplace restrictions, inasmuch as some state laws exclude small businesses even though these firms employ a considerable percentage of the US workforce. $^{43}$

The rating system focused its targets on enforcement related issues to include a rating on two topics: penalties (item 8) and designation of an enforcement authority (item 9). A state could meet the target for the penalty item if state law required a graduated penalty scheme applicable to both smokers and to proprietors/employers. The item 9 target was met when state law specified an enforcement authority and required sign posting.

The committee established separate criteria for rating each of the nine items. The scoring structure for rating each item may be interpreted as follows:

+5 Exceeds target (where applicable): outstanding

+4 Meets target: excellent

+3 Meets $\sim 75 \%$ of target: good

+2 Meets $\sim 50 \%$ of target: fair

+1 Meets $\sim 25 \%$ of target: minimal

0 No effective item: none

It is important to note that the target percentages for the seven location restrictions are subjective and do not, necessarily, equate to a certain percentage reduction in exposure to ETS. The appendix should be consulted for details on the specific criteria for rating each item.

\section{Scoring for preemption}

The committee devised a separate set of scores for state laws that included language on preemption. State preemption is in effect when a state government regulates an area or subject matter so that its law supercedes those of lower jurisdictions. ${ }^{44}{ }^{45}$ When a state law uniformly preempted all local ordinances related to the clean indoor air items of interest, the state score was reduced by two points on each of the nine items of interest, with the lowest possible score being zero. ${ }^{11}$ As noted below, to enable the committee to assess further the preemption effect on the extensiveness of the state laws, we developed two sets of total scores-one without preemption and one with preemption.

\section{Coding of the laws and inter-rater agreement}

Two raters independently reviewed the SCLD clean indoor air current status records and developed initial ratings for 1993 through 1999. Following these initial ratings, the individual ratings were compared and coded to form a final consensus rating.* To ensure the reliability of the ratings methodology, a third rater reviewed the current status records for all states

*A copy of the decision rules for developing the clean indoor air ratings is available from the corresponding author. 


\begin{tabular}{|c|c|c|c|c|c|c|c|c|}
\hline State & 1993 & 1994 & 1995 & 1996 & 1997 & 1998 & 1999 & $\Delta$ 1993-1999 \\
\hline Alabama & 0 & 0 & 0 & 0 & 0 & 0 & 0 & 0 \\
\hline Alaska & 18 & 18 & 18 & 18 & 18 & 18 & 18 & 0 \\
\hline Arizona & 6 & 6 & 6 & 6 & 6 & 6 & 10 & 4 \\
\hline Arkansas & 5 & 5 & 5 & 5 & 5 & 5 & 5 & 0 \\
\hline California & 13 & $18(2)$ & $18(2)$ & $18(2)$ & $18(2)$ & $18(2)$ & $18(2)$ & 5 \\
\hline Colorado & 3 & 4 & 4 & 4 & 4 & 4 & 4 & 1 \\
\hline Connecticut & $8(2)$ & $8(2)$ & $8(2)$ & $8(2)$ & $8(2)$ & $8(2)$ & $8(2)$ & 0 \\
\hline Delaware & 0 & $17(5)$ & $17(5)$ & $17(5)$ & $17(5)$ & $17(5)$ & $17(5)$ & 17 \\
\hline District of Columbia & 12 & 12 & 12 & 12 & 12 & 12 & 12 & 0 \\
\hline Florida & 20 (7) & $20(7)$ & $20(7)$ & $20(7)$ & 20 (7) & $20(7)$ & $20(7)$ & 0 \\
\hline Georgia & 2 & 6 & 6 & 6 & 6 & 6 & 6 & 4 \\
\hline Hawaii & 12 & 12 & 12 & 12 & 12 & 12 & 12 & 0 \\
\hline Idaho & 9 & 9 & 9 & 9 & 9 & 9 & 9 & 0 \\
\hline Illinois & $10(2)$ & $10(2)$ & $13(5)$ & $13(5)$ & $13(5)$ & $13(5)$ & $13(5)$ & 3 \\
\hline Indiana & 5 & 5 & 5 & 5 & 5 & 9 & 12 & 7 \\
\hline lowa & $10(0)$ & $10(0)$ & $10(0)$ & $10(0)$ & $10(0)$ & $10(0)$ & $10(0)$ & 0 \\
\hline Kansas & 13 & 14 & 14 & 14 & 14 & 14 & 14 & 1 \\
\hline Kentucky & 3 & $3(0)$ & $3(0)$ & $3(0)$ & $3(0)$ & $3(0)$ & $3(0)$ & 0 \\
\hline Louisiana & $11(2)$ & 16 (7) & 16 (7) & 16 (7) & 16 (7) & 16 (7) & 16 (7) & 5 \\
\hline Maine & $9^{1-1}$ & 9 & 9 & 9 & 9 & 9 & 9 & 0 \\
\hline Maryland & 3 & 3 & 23 & 23 & 23 & 23 & 23 & 20 \\
\hline Massachusetts & 10 & 10 & 10 & 10 & 10 & 10 & 10 & 0 \\
\hline Michigan & 16 & 16 & 16 & 16 & 16 & 16 & 16 & 0 \\
\hline Minnesota & 13 & 13 & 13 & 13 & 13 & 13 & 13 & 0 \\
\hline Mississippi & 0 & 0 & 0 & 0 & 0 & 0 & 0 & 0 \\
\hline Missouri & 14 & 14 & 14 & 14 & 14 & 14 & 14 & 0 \\
\hline Montana & 12 & 12 & 12 & 12 & 12 & 12 & 12 & 0 \\
\hline Nebraska & 9 & 9 & 9 & 9 & 9 & 9 & 11 & 2 \\
\hline Nevada & $13(4)$ & $13(4)$ & $13(4)$ & $13(4)$ & $13(4)$ & $13(4)$ & $13(4)$ & 0 \\
\hline New Hampshire & 15 & 15 & 15 & 15 & 15 & 15 & 15 & 0 \\
\hline New Jersey & 11 & 11 & 11 & 11 & 11 & 14 & 14 & 3 \\
\hline New Mexico & 6 & 6 & 6 & 6 & 6 & 6 & 6 & 0 \\
\hline New York & 16 & 19 & 19 & 19 & 19 & 19 & 19 & 3 \\
\hline North Carolina & $1(0)$ & $1(0)$ & $1(0)$ & $1(0)$ & $1(0)$ & $1(0)$ & $1(0)$ & 0 \\
\hline North Dakota & 14 & 14 & 14 & 14 & 14 & 14 & 14 & 0 \\
\hline Ohio & 6 & 9 & 9 & 9 & 9 & 9 & 9 & 3 \\
\hline Oklahoma & $6(0)$ & $10(1)$ & $10(1)$ & $10(1)$ & $10(1)$ & $10(1)$ & $10(1)$ & 4 \\
\hline Oregon & 9 & 9 & 9 & 9 & 9 & 9 & 9 & 0 \\
\hline Pennsylvania & $8(0)$ & $8(0)$ & $8(0)$ & $8(0)$ & $8(0)$ & $8(0)$ & $8(0)$ & 0 \\
\hline Rhode Island & 13 & 13 & 13 & 13 & 13 & 13 & 13 & 0 \\
\hline South Carolina & 9 & 11 & 11 & $11(3)$ & $11(3)$ & $11(3)$ & $11(3)$ & 2 \\
\hline South Dakota & 4 & 5 & $5(0)$ & $5(0)$ & $5(0)$ & $5(0)$ & $5(0)$ & 1 \\
\hline Tennessee & 0 & 0 & $6(0)$ & $6(0)$ & $6(0)$ & $6(0)$ & $6(0)$ & 6 \\
\hline Texas & 6 & 6 & 6 & 6 & 6 & 6 & 6 & 0 \\
\hline Utah & 17 & $31(14)$ & $31(14)$ & $31(14)$ & $31(14)$ & $31(14)$ & $31(14)$ & 14 \\
\hline Vermont & 9 & 9 & 13 & 13 & 13 & 13 & 13 & 4 \\
\hline Virginia & $9(0)$ & $13(2)$ & $13(2)$ & $13(2)$ & $13(2)$ & $13(2)$ & $13(2)$ & 4 \\
\hline Washington & 11 & 11 & 11 & 11 & 11 & 11 & 11 & 0 \\
\hline West Virginia & 3 & 3 & 3 & 3 & 3 & 3 & 3 & 0 \\
\hline Wisconsin & 12 & 15 & 15 & 15 & 15 & 15 & 15 & 3 \\
\hline Wyoming & 0 & 0 & 0 & 0 & 0 & 0 & 0 & 0 \\
\hline Mean & 8.71 & 10.02 & 10.67 & 10.67 & 10.67 & 10.80 & 10.98 & NA \\
\hline Median & 9 & 10 & 11 & 11 & 11 & 11 & 11 & NA \\
\hline
\end{tabular}

*Scores with preemption penalties are shown in parentheses.

for the baseline year (1993) and independently assigned ratings. The overall inter-rater agreement for the coding schema was $86.1 \%$. Agreement rates were highest for childcare facilities (96.1\%), restaurants (96.1\%), and recreational/cultural facilities $(94.1 \%)$. The lowest agreement rates were for the penalty items $(70.6 \%)$ and the enforcement items $(74.5 \%)$. The committee had expected some difficulty in rating the penalty and enforcement items, given the states' diverse approaches to drafting enforcement related language.

\section{RESULTS}

Detailed information on the state specific values for each of the nine categories for all years is available on the SCLD website (www.scld-nci.net). Data on mean scores and cumulative results are summarised below and presented on the SCLD website.

\section{Mean scores for individual restrictions}

The mean scores across states on each of the individual items are presented in table 2 . Overall mean scores across all of the items (items 1-9) ranged from 0.97 in 1993 to 1.22 in 1999, on a scale where a +4 indicated that the target goals across the items were achieved.

For the most part, state laws restricting smoking in the seven locations of interest were relatively weak. As table 2 indicates, the overall mean score across the location restrictions ranged from 0.72 in 1993 to a high of 0.98 in 1999. While still far from the target goal of +4 , smoking restrictions were most extensive in relation to schools, childcare facilities, and government worksites. Restrictions were less common in recreational/cultural facilities, private worksites, restaurants, and retail stores.

State scores on the penalty and enforcement items were higher than those for the location restrictions. The overall 
Table 4 Number of states with preemption penalties in clean indoor air ratings by item, 1993-1999

\begin{tabular}{|c|c|c|c|c|c|c|c|c|c|}
\hline Item & 1993 & 1994 & 1995 & 1996 & 1997 & 1998 & 1999 & $\begin{array}{l}\text { Change } \\
\text { 1993-1999 }\end{array}$ & $\begin{array}{l}\Delta \text { (\%) } \\
\qquad 993-1999\end{array}$ \\
\hline 1. Government worksites & 8 & 11 & 11 & 12 & 12 & 12 & 12 & 4 & 50.00 \\
\hline 2. Private worksites & 5 & 8 & 8 & 8 & 8 & 8 & 8 & 3 & 60.00 \\
\hline 3. Schools & 7 & 11 & 13 & 14 & 14 & 14 & 14 & 7 & 100.00 \\
\hline 4. Childcare facilities & 4 & 8 & 10 & 11 & 11 & 11 & 11 & 7 & 175.00 \\
\hline 5. Restaurants & 8 & 11 & 11 & 11 & 11 & 11 & 11 & 3 & 37.50 \\
\hline 6. Retail & 6 & 9 & 9 & 9 & 9 & 9 & 9 & 3 & 50.00 \\
\hline 7. Recreation/cultural facilities & 6 & 10 & 12 & 13 & 13 & 13 & 13 & 7 & 117.00 \\
\hline 8. Penalties & 9 & 13 & 15 & 16 & 16 & 16 & 16 & 7 & 77.78 \\
\hline 9. Enforcement & 10 & 13 & 14 & 15 & 15 & 15 & 15 & 5 & 50.00 \\
\hline Any item & 10 & 14 & 16 & 17 & 17 & 17 & 17 & 7 & 70.00 \\
\hline
\end{tabular}

mean rating for the combined penalty and enforcement items ranged from 1.83 in 1993 to 2.06 in 1999. Across all years, penalty items in the state laws were slightly stronger than the enforcement items; however, more states achieved the target score for enforcement than in any other area covered by the ratings (14 states as of the end of 1999).

\section{Cumulative and summary scores}

Table 3 presents the total summary scores for each state for 1993 through 1999, as well as the change in scores between 1993 and 1999. A state that achieved the target across all nine items would have received 36 points plus 6 additional points for exceeding the target on six of the nine items, for a total of 42 points. Generally, the scores fell well below the target score across all years; however, Utah scored 31 points in 1994 through 1999. Between 1993 and 1999, the scores increased for 22 states, with Maryland demonstrating the most dramatic increase over time (20 points). Three states-Alabama, Mississippi, and Wyoming—scored zero points across all seven years.

As tables 2 and 3 indicate, state laws related to the items of interest did not substantively change between 1995 and 1997; therefore, the total summary scores for each state did not change between these years. The overall mean summary score across all states ranged from 8.71 in 1993 to 10.98 in 1999. Thus, as of the end of 1999, all of the states combined only achieved slightly more than $26 \%$ of the target restrictions examined in this study. The minimum and maximum scores ranged from 0 to 20 in 1993 and 0 to 31 in 1994 through 1999. In 1993 and 1994, the modal score was 9, while the modal score in 1995 through 1999 was 13. It is important to recall, however, that the per item scores were higher for the penalty and enforcement items. Thus, achieving a total summary score of nine did not necessarily equate with a minimal $(+1)$ rating on each of the nine items.

\section{Measuring the effect of preemption}

As table 4 reveals, the number of states enacting clean indoor air laws containing items eliminating or limiting local authority increased steadily between 1993 and 1996 and then stabilised after that point. ${ }^{44}{ }^{45}$ At the end of $1999,41 \%$ more states had laws in place that preempted local ordinances than had such laws at the end of 1993. As of the end of 1999, preemption affected the scores of 17 states. Preemptive items were most common in relation to penalty and enforcement items followed by schools, recreational/cultural facilities, and government worksites.

When accounting for the preemption factor, state scores were negatively affected for all years after enactment of preemption. The overall mean summary score for all of the states combined, when accounting for preemption, ranged from 7.2 in 1993 to 8.02 in 1999. As of the end of 1999, preemption reduced the overall mean summary score by $27 \%$. Utah, California, and Florida's scores were most dramatically effected by preemption (table 3). When accounting for preemption, their scores were reduced by 17,16 , and 13 points, respectively.

\section{DISCUSSION}

This study is particularly timely since tobacco control programmes are established in all 50 states and the District of Columbia. The methodology developed and the results reported herein can be used as one measure by which the state tobacco control programmes can monitor their own progress in meeting key objectives.

Ratings results show that states have enacted clean indoor air laws with more frequent restrictions on government workplaces, schools, and day care facilities than on private workplaces, restaurants, and recreational/cultural facilities. Further research would be worthwhile to examine the extent to which this result is influenced by factors outside of public health-for example, the political calculation that antismoking measures for government worksites and to protect children are more likely to be enacted than similar measures for private businesses.

Moreover, while it is encouraging that items for enforcement of the laws that do exist are the strongest part of the ratings, this indicates that states are calling for enforcement of weak items. The NCI committee saw the same pattern observed when developing the youth access ratings-weak laws on the books. ${ }^{11}$ When combined with ratings for youth access laws, the states are very far from setting high benchmarks to protect public health. The findings also shed light on the fact that implementation of state tobacco control programs-not simply adoption of clean indoor air laws-is critical.

Also, as with the youth access topic area, preemption was a key factor in the clean indoor air ratings. ${ }^{11}$ As noted above, the number of states enacting items to eliminate or limit local authority to adopt tobacco control legislation increased steadily between 1993 and 1996, but stabilised thereafter. ${ }^{44}{ }^{45}$ State preemption is significant in the clean indoor air legislative arena, since local ordinances restricting smoking are well established across the USA. ${ }^{46-48}$ Numerous internal industry documents released during the Minnesota attorney general's lawsuit against tobacco product manufacturers confirm that for the past decade the tobacco industry's chief legislative goal at the state level has been the enactment of preemption legislation. ${ }^{49-52}$

However, public health organisations strongly oppose preemptive tobacco control laws. ${ }^{53}{ }^{54}$ Formal opposition to preemption is found in the federal government's "Healthy People 2010" report. ${ }^{8}$ Opponents of preemption express concern that legislation at one level of government is being used to weaken the strength of a lower level of government and, consequently, that public health standards are compromised. Opponents also cite the greater success of local level public education and the potential for greater compliance that can occur with local level, as opposed to state level, clean indoor air initiatives. ${ }^{46}$

The NCI committee felt strongly that state laws that include preemption should be identified and that specific items of the 
law to which preemption applies should not be scored on the same par as non-preemptive items. Under the described rating system, a state score is calculated exclusive of information about preemption. However, an alternative score is also calculated to consider preemption, thus identifying and "penalising" individual states for preemptive language (table 3); this alternative score more fully reflects the content and extensiveness of the law.

\section{Limitations and uses}

The ratings system described herein applies to state laws only. State regulations and executive orders, which may be significant policy instruments for a given state, were not examined for this analysis. Thus, the ratings structure may provide information on only one component of a state's clean indoor air policy.

Similarly, analysis of state legislation on indoor smoking represents only one level of governmental policy affecting ETS exposure. On the federal level, there has been only limited action with regard to indoor air quality. ${ }^{3}$ Instead, many of the most extensive clean indoor air items have been developed at the local levels of government. In fact, over the past two decades there has been a significant increase in the number of local ordinances aimed at limiting exposure to second hand smoke. Such ordinances are adopted by counties or other local entities in the USA and mandate restrictions for that locality only. ${ }^{478}$ The committee believes that the ratings model described here also could be adapted for rating the extensiveness of clean indoor air laws at the local levels of government. $^{12}$

Non-governmental, or voluntary, clean indoor air regulation also falls outside the framework of the described ratings system. For example, in the health care industry, a ban on smoking has emerged as an important factor in diminishing the risk of exposure to ETS in hospital settings. ${ }^{55}$ One study reported that $96 \%$ of hospitals were in compliance with the ban within two years of its implementation. ${ }^{56}$ Despite minimal clean indoor air restrictions for private workplaces in many state laws, individual businesses have been active in adopting their own smoking bans, which may account for the fact that a high percentage of the workforce in some states is reportedly covered by smoke-free policies. ${ }^{43}$

In addition to the aforementioned limitations of the rating system, the authors recognise inherent complexities in the structure of the ratings system itself. For example, the selection of location categories raises the potential criticism that public and private workplaces are placed on a par with retail stores and recreational/cultural facilities in terms of possible exposure to ETS. From a public health standpoint, it is probably more important to restrict smoking by worksite, where exposure is both prolonged and involuntary. For this study, these categories are effectively of equal weight; however, their purpose is to measure the comprehensiveness of a given state clean indoor air law in terms of the degree to which smoking is or is not permitted. Therefore, it is the individual adjustments within each category that measure the content of the law. Drawing on the most relevant and best available scientific data on the effects of different types of restrictions-ranging from a complete ban to few or no restrictions on indoor smoking ${ }^{34-36}$ - the committee designed a scale to correlate to the level of restrictiveness for the clean indoor air items identified for this study.

The high percentage of inter-rater agreement (89.1\%) for the categories identified as "public places" suggests strong reliability of the ratings system for interpreting the restrictiveness of statutory language of these items. Inter-rater agreement was lower for rating categories identified as "penalties" and "enforcement", a result that was predicted based

\section{What this paper adds}

Sources for data on state level clean indoor air laws in the USA exist in a number of formats; however, there has not been available a tool for systematic comparative analysis of these laws.

The ratings system described in this paper provides one measure for evaluating the extensiveness of state clean indoor air laws in nine areas of interest. A National Cancer Institute (NCl) advisory committee devised a ratings scale and, using data from the $\mathrm{NCl}^{\prime}$ s State Cancer Legislative Database (SCLD), determined state-by-state and summary scores for the years 1993 through 1999. Overall, scores for state laws restricting smoking in the areas of interest were relatively weak and were even lower when state level preemption measures were taken into account.

on the diverse approaches of states in drafting enforcement related items. State statutes differ on such matters as whether smokers and/or proprietors face sanctions for violations and on the type of enforcement authority if such an authority has been named. Moreover, clean indoor air laws have been characterised as self enforcing, although the amount of data on compliance is limited. ${ }^{32} 33$ A few studies have considered other variables that may be significant; these variables include insufficient public information and/or education about the law and limited reinforcement actions in the years following the law's enactment. Examination of the implementation of clean indoor air laws was also beyond the scope of the ratings structure; however, the authors recognise the importance of studies in this area and hope that data from this ratings system may facilitate further analysis.

In summary, the authors recognise the limitations of this study. In addition, we recognise that critical assumptions were made about the health outcomes and estimates of exposure associated with the various smoking policies in the state laws; however, we contend that the rating system offers a reasonable framework for examining states' efforts in this area. The results of this analysis suggest that state laws, considered as a whole, establish only minimal clean indoor air restrictions in specified locations and, with increasing frequency, use preemption to prevent local jurisdictions from adopting measures that vary within states or are more restrictive than state laws.

Future applied research may seek to examine whether a rating system such as that described here could be applied to legislative studies in the USA at the local level and in other countries. ${ }^{12}$ In addition, it would be interesting to explore the relation, if any, between state scores on the youth access to tobacco ratings ${ }^{11}$ and the clean indoor air ratings to first ascertain whether or not different aspects of tobacco control are being given equal weight in the state legislatures, and second, to develop an overall measure of tobacco control legislation in the states. Other research would be well served to explore the relation between the clean indoor air ratings and state level ETS exposure based on the US Census Bureau's Current Population Survey or other data sets.

\section{ACKNOWLEDGMENT}

The authors acknowledge Liza A Fues, JD, of The MayaTech Corporation for her significant contribution to the legislative analysis required for this evaluation. This study was supported under contract number N02-PC-75007 and 282-98-0014, Task Order 8, from the National Cancer Institute (NCI) and utilised data from the NCI State Cancer Legislative Database Program. 


\section{APPENDIX: DECISION CRITERIA FOR RATING STATE CLEAN INDOOR AIR LAWS}

(1) For all items, +4 represents the target item.

(2) For all items, state preemption of stricter local ordinances reduces any score by 2 points (with a minimum score of 0 ).

(3) Maximum score that a state can receive is 42 points.

\section{Item 1: Government worksites are 100\% smokefree (points: decision criteria)}

+5: $100 \%$ of government worksites and grounds (or a specified distance from entries/exits) are smokefree, no exemptions

+4: Government worksites are 100\% smokefree, no exemptions

+3: No smoking permitted in government worksites unless restricted to enclosed, separately ventilated designated smoking areas or government worksites are $100 \%$ smokefree, with a minimal exemption (for example, worksites with five or fewer employees, privately enclosed offices used exclusively by smokers, or other narrow exemption (for example, based on smoker density) exemption)

+2 : Smoking in government worksites restricted to designated smoking areas which are separate and enclosed or to enclosed, separately ventilated designated smoking areas, with a minimal exemption

+1 : Smoking in government worksites restricted only to designated smoking areas; or to designated smoking areas which are separate and enclosed, with a minimal exemption, or any stricter requirement that applies to some but not all types of worksites (for example, warehouses exempted) and/or includes more than a minimal exemption

0 : No restrictions, or requirement(s) that smoking be permitted

\section{Item 2: Private worksites are $100 \%$ smokefree (points:} decision criteria)

+5: $100 \%$ of private worksites and grounds (or a reasonable distance from entries/exits) are smokefree, no exemptions

+4: Private worksites are $100 \%$ smokefree, no exemptions

+3: No smoking permitted in private worksites unless restricted to enclosed, separately ventilated designated smoking areas or private worksites are $100 \%$ smokefree, with a minimal exemption (for example, worksites with five or fewer employees, privately enclosed offices used exclusively by smokers, or other narrow exemption (for example, based on smoker density exemption)

+2 : Smoking in private worksites restricted to designated smoking areas which are separate and enclosed or to enclosed, separately ventilated designated smoking areas, with a minimal exemption

+1 : Smoking in private worksites restricted only to designated smoking areas; or to designated smoking areas which are separate and enclosed, with a minimal exemption, or any stricter requirement that applies to some but not all types of worksites (for example, warehouses exempted) and/or includes more than a minimal exemption

0 : No restrictions, or requirement(s) that smoking be permitted

Item 3: No smoking permitted during school hours in schools, on school grounds (or a reasonable distance from entries/exits) and at school events (points: decision criteria)

+5: No smoking permitted at any time in school facilities including-but not limited to-buildings, school grounds (or reasonable distance from entries/exits)
+4 : No smoking permitted in schools during school hours or while school activities are being conducted

+3: No smoking permitted in schools during school hours only or any stricter requirement that restricts smoking to enclosed, separately ventilated designated smoking areas

+2 : Smoking in schools during school hours restricted only to designated smoking areas which are separate and enclosed

+1 : Smoking in schools during school hours restricted only to designated smoking areas, or any stricter requirement that includes more than minimal exemption(s) (for example, all private schools explicitly exempted)

0 : No restrictions, or requirement(s) that smoking be permitted

Item 4: No smoking permitted during operating hours in childcare facilities (explicitly including licensed home based facilities) (points: decision criteria)

+4: No smoking permitted during operating hours in childcare facilities (explicitly including licensed home based facilities)

+3: No smoking permitted in child care facilities unless restricted to enclosed, separately ventilated designated smoking areas

+2 : Smoking in childcare facilities restricted to designated smoking areas which are separate and enclosed

+1 : Smoking in childcare facilities restricted only to designated smoking areas or restrictions on smoking in childcare facilities that apply to some but not all facilities (for example, home based facilities are explicitly exempt)

0 : No restrictions, or requirement(s) that smoking be permitted

Item 5: Restaurants (including bar areas of restaurants) are $100 \%$ smokefree (points: decision criteria)

+5: $100 \%$ of restaurants, bars, and taverns are smokefree, including outdoor seating

+4 : Restaurants (explicitly including bar areas of restaurants) are $100 \%$ smokefree

+3: No smoking permitted in restaurants (including bar areas of restaurants) unless restricted to enclosed, separately ventilated designated smoking areas

+2 : Smoking in restaurants restricted to designated smoking areas which are separate and enclosed

+1 : Smoking in restaurants restricted only to designated smoking areas or restrictions on smoking that apply to some but not all restaurants (for example, size exemptions)

0 : No restrictions, or requirement(s) that smoking be permitted

Item 6: Retail stores or retail businesses open to the public are $100 \%$ smokefree (points: decision criteria)

+4 : Retail stores or retail businesses open to the public are $100 \%$ smokefree

+3: No smoking permitted in retail stores or retail businesses open to the public unless restricted to enclosed, separately ventilated designated smoking areas

+2 : Smoking in retail stores or retail businesses open to the public restricted to designated smoking areas which are separate and enclosed

+ l: Smoking in retail stores or retail businesses open to the public restricted only to designated smoking areas or restrictions on smoking that apply to some but not all retail stores or retail businesses open to the public

0 : No restrictions, or requirement(s) that smoking be permitted 
Item 7: Recreational and cultural facilities are $100 \%$ smokefree (points: decision criteria)

+4 : Recreational and cultural facilities are $100 \%$ smokefree

+3 : No smoking permitted in recreational and cultural facilities unless restricted to enclosed, separately ventilated designated smoking areas

+2 : Smoking in recreational and cultural facilities restricted to designated smoking areas which are separate and enclosed +1 : Smoking in recreational and cultural facilities restricted only to designated smoking areas or restrictions on smoking that apply to some but not all recreational and/or cultural facilities

0 : No restrictions, or requirement(s) that smoking be permitted

\section{Item 8: Establish a system of penalties or fines, applicable to smokers and to proprietors/employers, for any violations of clean indoor air legislation (points: decision criteria)}

+5: Graduated penalties or fines, applicable to smokers and to proprietors/employers, for repeated violations of clean indoor air legislation

+4: Penalties or fines, applicable to smokers and to proprietors/employers, for any violation of clean indoor air legislation

+3: Penalties or fines, applicable to smokers and to proprietors/employers, for any violation of clean indoor air legislation, but with the possibility of delayed penalties (for example, triggered after more than one offense)

+2 : Penalties or fines, applicable to either smokers or to proprietors/employers or any of the above applicable to most but not all specified clean indoor air items

+1 : Penalties or fines, applicable to either smokers or to proprietors/employers, with the possibility of delayed penalties (for example, triggered after more than one offense) or any of the above applicable to only a limited number of specified clean indoor air items

0 : None of the above

Note: Intent requirement or affirmative defences or waivers that require only minimal (or possibly minimal) compliance with the law reduce any score by 1 point.

\section{Item 9: Designate an enforcement authority for clean indoor air legislation and require sign posting (points: decision criteria)}

+5: Designate an enforcement authority for clean indoor air legislation, and require the agency or other officials to conduct compliance inspections and require sign posting

+4 : Designate an enforcement authority for clean indoor air legislation and require sign posting

+3: Designate an enforcement authority for clean indoor air legislation, but no requirement for sign posting

+2 : Designate an enforcement authority for certain sites only, and require sign posting

+1 : Designate an enforcement authority for certain sites only, but no requirement for sign posting, or requirement for sign posting only (no enforcement authority designated for any site) 0: No item

\section{Authors' affiliations}

J F Chriqui, M Frosh, The MayaTech Corporation, Silver Spring, Maryland, USA

R C Brownson, Department of Community Health and Prevention Research Center, School of Public Health, St Louis University, St Louis, Missouri, USA
*D M Shelton, Division of STD Prevention, National Center for HIV, STD and TB Prevention, Centers for Disease Control and Prevention, Atlanta, Georgia, USA

R C Sciandra, Center for Tobacco-Free New York, Loudonville, New York, USA

†R Hobart, Alpine, Texas, USA

P H Fisher, Campaign for Tobacco-Free Kids, Washington DC, USA

$¥ R$ el Arculli, National Cancer Institute, National Institutes of Health, Bethesda, Maryland, USA

M H Alciati, Management Solutions for Health, Reston, Virginia, USA

*The contributions herein of Dana Shelton are hers as an author and may not necessarily reflect the opinions, official policy, or position of the Centers for Disease Control and Prevention, DHHS. Ms Shelton's contributions were done principally while in the Office on Smoking and Health at the CDC.

†The contributions herein of Robin Hobart were done principally while at the Americans for Nonsmokers' Rights.

¥The contributions herein of Regina el Arculli are hers as an author and may not necessarily reflect the opinions, official policy, or position of the National Cancer Institute, NIH, DHHS

\section{REFERENCES}

1 US Department of Health and Human Services. The health consequences of involuntary smoking: a report of the Surgeon General. Rockville, Maryland: US Dept of Health and Human Services, Public Health Service, Centers for Disease Control, Center for Health Promotion and Education, Office on Smoking and Health, 1986. (DHHS Publication No. (CDC) 87-8398)

2 National Research Council. Environmental tobacco smoke: measuring exposures and assessing health effects. Washington DC: National Academy Press, 1986.

3 Brownson RC, Eriksen MP, Davis RM, et al. Environmental tobacco smoke: health effects and policies to reduce exposure. Annu Rev Public Health 1997;18:163-85.

4 US Department of Health and Human Services. Reducing tobacco use: a report of the Surgeon General. Atlanta, Georgia: US Department of Health and Human Services, Centers for Disease Control and Prevention, National Center for Chronic Disease Prevention and Health Promotion, Office on Smoking and Health, 2000.

5 Environmental Protection Agency. Respiratory health effects of passive smoking: lung cancer and other disorders. Washington DC: Environmental Protection Agency; 1992. EPA publication EPA/600/6-90/006F.

6 California Environmental Protection Agency. Health effects of exposure to environmental tobacco smoke. Sacramento, California: California Environmental Protection Agency, Office of Environmental Health Hazard Assessment, 1997.

7 National Institute for Occupational Safety and Health. Environmental tobacco smoke in the workplace: lung cancer and other health effects. [Current Intelligence Bulletin 54 posted on the world wide web.] Washington, DC: NIOSH, 1991. DHHS NIOSH publication 91-108. Accessed 13 March 1998. URL: http://www.cdc.gov/niosh/ 91108 54.html

8 US Department of Health and Human Services, Healthy people 2010: understanding and improving health, 2nd ed. Washington DC: US Government Printing Office, 2000.

9 Shelton DM, Alciati MH, Chang MM, et al. State laws on tobacco control - United States, 1995 (CDC Surveillance Summaries). MMWR Morb Mortal Wkly Rep 1995;44(SS-6).

10 Fishman JA, Allison H, Knowles SB, et al. State laws on tobacco control - United States, 1998 (CDC Surveillance Summaries). MMWR Morb Mortal Wkly Rep 1999;48(SS-3).

11 Alciati MH, Frosh, M, Green SB, et al. State laws on youth access to tobacco in the United States: measuring their extensiveness with a new rating system. Tobacco Control 1998;7:345-52.

12 Wakefield $M$, Chaloupka F. Improving the measurement and use of tobacco control "inputs". Tobacco Control 1998;7:333-5.

13 Luke DA, Stamatakis KA, Brownson RC. State youth access to tobacco control policies and youth smoking behavior in the United States. Am J Prev Med 2000; 19:180-7.

14 National Institutes of Health. National Cancer Institute. Clean indoor air: a guide to developing policy. [Number two in a series of four policy guides. The American stop smoking intervention study.] Bethesda, Maryland: NIH, 1994.

15 Brownson RC, Davis JR, Jackson-Thompson J, et al. Environmental tobacco smoke awareness and exposure: impact of a statewide clean indoor air law and the report of the US Environmental Protection Agency Tobacco Control 1995;4:132-8

16 Borland R, Pierce JP, Burns DM, et al. Protection from environmental tobacco smoke in California. The case for a smoke-free workplace. JAMA 1992; 268:749-52.

17 Hammond SK, Sorensen G, Youngstrom R, et al. Occupational exposure to environmental tobacco smoke. JAMA 1995; 274:956-60.

18 Pierce JP, Shanks TG, Pertschuk M, et al. Do smoking ordinances protect nonsmokers from environmental tobacco smoke at work? Tobacco Control 1994;3:15-20. 
19 Patten CA, Pierce JP, Cavin SW, et al. Progress in protecting non-smokers from environmental tobacco smoke in California workplaces. Tobacco Control 1995;4:139-44.

20 Chapman S, Borland R, Scollo M, et al. The impact of smoke-free workplaces on declining cigarette consumption in Australia and the United States. Am J Pub Health, 1999:89:1018-23.

21 Farkas AJ, Gilpin EA, Distefan JM, et al. The effects of household and workplace smoking restrictions on quitting behaviors. Tobacco Control 1999:8:261-5.

22 Farrelly MC, Evans WN, Sfekas AES. The impact of workplace smoking bans: results from a national survey. Tobacco Control 1999;8:272-7.

23 Hopkins DP, Briss PA, Ricard CJ, et al. Reviews of evidence regarding interventions to reduce tobacco use and exposure to environmental tobacco smoke. Am J Prev Med 2001;20:16-66.

24 Ashley MJ, Ferrence R. Reducing children's exposure to environmental tobacco smoke in homes: issues and strategies. Tobacco Control 1998;7:61-5.

25 Sweda EL, Gottlieb MA, Porfiri RC. Protecting children from exposure to environmental tobacco smoke. Tobacco Control 1998;7:1-2.

26 Wakefield MA, Chaloupka FJ, Kaufman NJ, et al. Effect of restrictions on smoking at home, at school, and in public places on teenage smoking: a cross-sectional study. BN 2000;321:333-7.

27 Biener L, Fitzgerald G. Smoky bars and restaurants: who avoids them and why? J Public Health Management Practice 1999;5:74-8.

28 Biener L, Siegel M. Behavior intentions of the public after bans on smoking in restaurants and bars. Am J Public Health 1997;87:2042-4.

29 Glantz SA, Smith LR. The effect of ordinances requiring smoke-free restaurants and bars on revenues: a follow-up. Am J Public Health 1997:87:1687-93.

30 Siegel $\mathbf{M}$. Involuntary smoking in the restaurant workplace. A review of employee exposures and health effects. JAMA 1993;270:490-3.

31 Jones K, Wakefield M, Turnbull DA. Attitudes and experiences of restauranteurs regarding smoking bans in Adelaide, South Australia. Tobacco Control 1999:8:62-6.

32 Hyland A, Cummings, KM, Wilson MP. Compliance with the New York City smoke-free air act. J Public Health Management Practice 1999;5:43-52.

33 Rigotti NA, Stoto MA, Schelling TC. Do businesses comply with a no-smoking law? Assessing the self-enforcement approach. Prev Med 1994;23:223-9.

34 Repace JL, Lowrey $\mathrm{AH}$. A quantitative estimate of nonsmokers' lung cancer risk from passive smoking. Env Int 1985;11:3-22.

35 Repace JL, Lowrey AH. An enforceable indoor air quality standard for environmental tobacco smoke in the workplace. Risk Anal 1993;13:463-75.

36 Repace JL. Risk management of passive smoking at work and at home. St Louis U Public Law Rev 1994;13:763-85.

37 Vaughan WM, Hammond SK. Impact of "designated smoking area" policy on nicotine vapor and particle concentrations in a modern office building. J Air Waste Manage Assoc 1990;40:1012-7.

38 Williams DC, Whitaker JR, Jennings WG. Measurement of nicotine in building air as an indicator of tobacco smoke levels. Environ Health Perspectives 1985;60:405-10.

39 Becker DM, Connor HF, Waranch R, et al. The impact of a total ban on smoking in the Johns Hopkins Children's Center. JAMA 1989;262:799-802.
40 Stillman FA, Becker DM, Swank RT, et al. Ending smoking at the Johns Hopkins Medical Institutions. An evaluation of smoking prevalence and indoor air pollution. JAMA 1990;264;1565-9.

41 Siegel M. Husten C, Merritt RK, et al. Effects of separately ventilated smoking lounges on the health of smokers: is this an appropriate public health policy? Tobacco Control 1995;4:22-9.

42 US Department of Labor, Bureau of Labor Statistics, Office of Employment and Unemployment Statistics, Division of Occupation and Administrative Statistics, ES-202 Program. Unpublished data: First Quarter 1995.

43 Shopland DR, Gerlach KK, Burns DM, et al. State-specific trends in smoke-free workplace policy coverage: the current population survey tobacco use supplement, 1993-1999. J Occup Environ Med 2001;43:680-6.

44 Siegel $M$, Carol J, Jordan J, et al. Preemption in tobacco control: review of an emerging public health problem. JAMA 1997;278:858-63.

45 Centers for Disease Control and Prevention. Preemptive state tobacco-control laws - United States, 1982-1998. MMWR Morb Mortal Wkly Rep 1999:47: $1112-4$

46 Jordan J, Pertschuk M, Carol J. Preemption in tobacco control: history, current issues, and future concerns. Berkeley, California: California Wellness Foundation, 1994

47 US Department of Health and Human Services. Major local tobacco control ordinances in the United States. Smoking and Tobacco Control Monograph 3. Bethesda, Maryland: National Institutes of Health, 1993 (NIH Publication No. 93-3532)

48 National Cancer Institute. State and local legislative action to reduce tobacco use. Smoking and Tobacco Control Monograph No. 11. Bethesda, Maryland: U.S. Department of Health and Human Services, National Institutes of Health, National Cancer Institute, 2000. (NIH Publication No. 00-4804)

49 Skolnick A. Cancer converts tobacco lobbyist: Victor L. Crawford goes on the record. JAMA 1995;274:199-202.

50 Tobacco Institute. Legislative opportunities: Year-to-date summary. Tobacco Institute website. 1989. Access date 2 June 1999. Bates No. TIMN 0015097 1989. URL: http://www.tobaccoinstitute.com.

51 Malmgren K. Phillip Morris Internal Memo. Tobacco Institute website. 1993. Access date 2 June 1999. Bates No. 2025660350. URL: http://www.tobaccoinstitute.com.

52 Donoho P, Morris R. Memorandum regarding lobbyist meeting-preemption exercise. Minnesota Tobacco Litigation. 1993 Bates No. ATX 090045377.

53 American Public Health Association. Public policy statements of the American Public Health Association: 1948-1994 collection. Washington DC: APHA, 1995.

54 Institute of Medicine. Growing up tobacco-free: preventing nicotine addiction in children and youths. Lynch BS, Bonnie R, eds. Washington, DC: National Academy Press 1994:214-5.

55 Joint Commission on Accreditation of Healthcare Organizations Accreditation manual for hospitals. Standard MA 1.3.15, 1.3.15.1. 1992.

56 Longo DR, Brownson RC, Kruse RL. Smoking bans in US hospitals: results of a national survey. JAMA 1995;274:488-91. 